\title{
Optical coherence tomography angiography features in patients with idiopathic full-thickness macular hole, before and after surgical treatment
}

This article was published in the following Dove Medical Press journal:

Clinical Interventions in Aging

\author{
Tomasz Wilczyński' \\ Anna Heinke' \\ Agata Niedzielska-Krycia' \\ Daria Jorg ${ }^{2}$ \\ Katarzyna \\ Michalska-Małecka ${ }^{1,3}$ \\ 'University Clinical Center, University \\ Hospital Medical University of Silesia, \\ Katowice, Poland; ${ }^{2}$ Department \\ of Sexuology, Woman's Health \\ Institute, School of Health Sciences \\ in Katowice, Medical University of \\ Silesia, Katowice, Poland; ${ }^{3}$ Department \\ of Ophthalmology, School of Medicine \\ in Katowice, Medical University of \\ Silesia, Katowice, Poland
}

Correspondence: Katarzyna MichalskaMałecka

Department of Ophthalmology, School of Medicine in Katowice, Medical University of Silesia, Ceglana Street 35, Katowice 40-5I4, Poland

Tel +48 $32358 \quad$ I 280

Email k.michalska.malecka@gmail.com
Purpose: To present optical coherence tomography (OCT) angiography features in patients with idiopathic full-thickness macular hole before and after vitrectomy.

Study design: Prospective case series study.

Materials and methods: Patients presenting with an idiopathic full-thickness macular hole (IMH) who underwent posterior vitrectomy with internal limiting membrane peeling and gas tamponade were included in the study. En face OCT and OCT angiography (OCTA) was performed pre- and postoperatively using $3 \times 3 \mathrm{~mm}$ scans (Optovue, XR Avanti). Foveal avascular zone (FAZ) area, macular hole size (MHS), central retinal thickness (CRT), macular parafoveal choriocapillary flow area (MCFA), and fovea vessel density (FVDS) were measured and assessed using OCTA. Best-corrected visual acuity (BCVA) was examined before and 3 months after surgery.

Results: Twenty-eight eyes of 28 patients were included in the study. The mean age of patient group was 68.28 years. The hole was closed in all eyes after the initial surgery. OCTA showed enlargement of FAZ and increased CRT in foveal area. Mean preoperative FAZ area was $0.39 \pm 0.07 \mathrm{~mm}^{2}$. En face images of the middle retina showed a range of preoperative cystic patterns surrounding the hole. BCVA was improved from $0.1 \pm 0.11$ preoperatively to $0.42 \pm 0.17$ postoperatively. Mean FAZ area was reduced to $0.24 \pm 0.07 \mathrm{~mm}^{2}$ postoperatively with resolution of macular hole and adjacent cystic areas. Mean CRT was reduced from $396 \pm 62.6 \mu \mathrm{m}$ preoperatively to $272 \pm 30.7 \mu \mathrm{m}$ postoperatively. After vitrectomy, the parafoveal choriocapillary flow area and FVDS of IMH eyes increased compared with the preoperative measurements. Conclusion: Quantitative evaluation of vascular and morphological changes following IMH surgery using OCTA shows the potential for recovery due to vascular and neuronal plasticity. OCTA showing vascular changes and their quantitative characteristics might be a useful tool for the assessment of macular holes before and after surgical treatment.

Keywords: angio-OCT, imaging, idopathic full thickness macular hole, vitrectomy, foveal avascular zone, central retinal thickness, choriocapillary flow area, foveal vessel density

\section{Introduction}

A macular hole $(\mathrm{MH})$ is a tissue defect in the foveal retina involving its full thickness from internal limiting membrane (ILM) to the outer segment of photoreceptor layer. Although full-thickness macular hole (FTMH) was first described by Knapp in $1869,{ }^{1}$ in relation to trauma, ${ }^{1-3}$ inflammation, and myopia, ${ }^{2,3}$ more recent clinical studies have shown that the vast majority are idiopathic ${ }^{4-16}$ and can occur with a prevalence of 1/3,300 usually in the sixth and seventh decades of life. ${ }^{17}$ There have been many studies investigating 
the cause of idiopathic $\mathrm{MH}$ that have implicated traction at the level of the vitreofoveal interface the underlying mechanism of FTMH formation. ${ }^{17,18}$

Pars plana vitrectomy (PPV) with gas tamponade first described by Kelly and Wende ${ }^{19}$ in 1991 is the method of choice in the treatment of MH. ${ }^{19}$ The introduction of vitrectomy has shown that surgical intervention is beneficial in $>90 \%$ of cases with FTMH in promoting the anatomical closure of $\mathrm{MH},{ }^{19-22}$ with subsequent improvement of visual acuity in the majority of cases. After the introduction of optical coherence tomography (OCT), fine morphologic changes in MHs have been extensively investigated, ${ }^{23-28}$ which has increased the understanding of development and healing of $\mathrm{MH}$.

Recovery of MH after vitrectomy begins with connection of the inner retina and formation of a bridge-like glial proliferation, followed by gradual restoration of the outer retina. ${ }^{29}$ Various changes in the fine structure of the macula, during the healing process, have been described..$^{30-42}$ These changes suggest that retinal morphologic remodeling occurs during the recovery process after MH surgery. Retinal vessels are another important component of the retinal structure and are known to be involved in the development and healing of retinal diseases. ${ }^{43}$

OCTA is a novel imaging platform that utilizes motion contrast to visualize retinal microvasculature in a rapid, noninvasive way (without the use of a dye) and depth-resolved fashion. This technology has enabled to investigate vascular changes in eyes with retinal disease ${ }^{44}$ Previous studies have reported characteristics of OCTA images in eyes with MH. ${ }^{45,46}$ In this study, we investigated the characteristics of the foveal structure and retinal microvasculature in eyes with MH before and after surgery using OCTA.

\section{Materials and methods}

This prospective case series study comprises 28 consecutive patients who underwent vitrectomy for an idiopathic $\mathrm{MH}$ and a follow-up examination 3 months after surgery using OCTA. All procedures took place at Professor K. Gibinski University Clinical Center, Medical University of Silesia, Katowice, Poland, between April 2016 and January 2017. The research was approved by Bioethics Committee of Silesian Medical Chamber in Katowice (Nr 8/2017). All patients provided written informed consent, and this study was conducted in accordance with the Declaration of Helsinki. We included cases of idiopathic $\mathrm{MH}$. The patient group had a mean age of 68.28 years and included 9 males and 19 females. Fifteen patients were phakic and 13 pseudophakic. We excluded patients with history of trauma, high myopia (spherical equivalent $\geq 6.0$ diopters or axial length $26 \mathrm{~mm}$ ), $\mathrm{MH}$ combined with retinal detachment, reoperation for unclosed MH after vitrectomy, other vitreoretinal disease, glaucoma, uveitis or retinitis in history, patients with retinal dystrophy and central retinal degeneration, anti-vascular endothelial growth factor treatment in history, patients with cataract, or patients who underwent cataract surgery 3 months prior to PPV. We excluded patients with poor OCTA image quality (signal strength index $<50$ ). In cases of bilateral $\mathrm{MH}$, the first affected eye was included in the analysis. Two surgeons performed PPV with ILM peeling and SF6 gas tamponade in all cases. ILM peeling was performed symmetrically around the fovea after staining with trypan blue. After the operation, the patient maintained a facedown position for 7 days. Each patient underwent a comprehensive ophthalmic examination pre- and postoperatively, including measurement of best-corrected visual acuity (BCVA) using Snellen charts, slit-lamp biomicroscopy with dilated Volk 90D fundoscopy, Goldmann applanation tonometry, and cross-sectional OCT as well as OCTA images using a commercial SD-OCT system (RTVue-XR Avanti, Optovue, Inc, Fremont, CA, USA) for imaging. The OCT images were used to measure the preoperative basal and minimum diameters of the $\mathrm{MH}$. The pre- and postoperative foveal thickness was determined from the OCTA images.

The AngioVue OCTA device (Optovue, Inc) was used to obtain amplitude-decorrelation angiography images. All the OCTA measurements were performed preoperatively and 3 months after vitrectomy.

The scanning area was captured in $3 \times 3 \mathrm{~mm}$ sections centered on the fovea. Only images with a signal strength index $>50$ were used, and images with motion artifacts and other artifacts were excluded. The en face images of the superficial capillary plexus (SCP) were segmented with an inner boundary at $3 \mu \mathrm{m}$ beneath the inner limiting membrane and an outer boundary at $15 \mu \mathrm{m}$ beneath the inner plexiform layer. The en face images of the deep capillary plexus (DCP) were segmented with inner and outer boundaries at 15 and $70 \mu \mathrm{m}$, respectively, beneath the inner plexiform layer. The segmentation errors in SCP and DCP slices in preoperative MH B-scans are due to central retinal defect and thickening associated with $\mathrm{MH}$.

Calculation of foveal avascular zone (FAZ) area was performed on the superficial retinal OCTA slab (SCP) using the nonflow function of the AngioAnalytics imaging software embedded in the AngioVue OCTA device (Figure 1). 

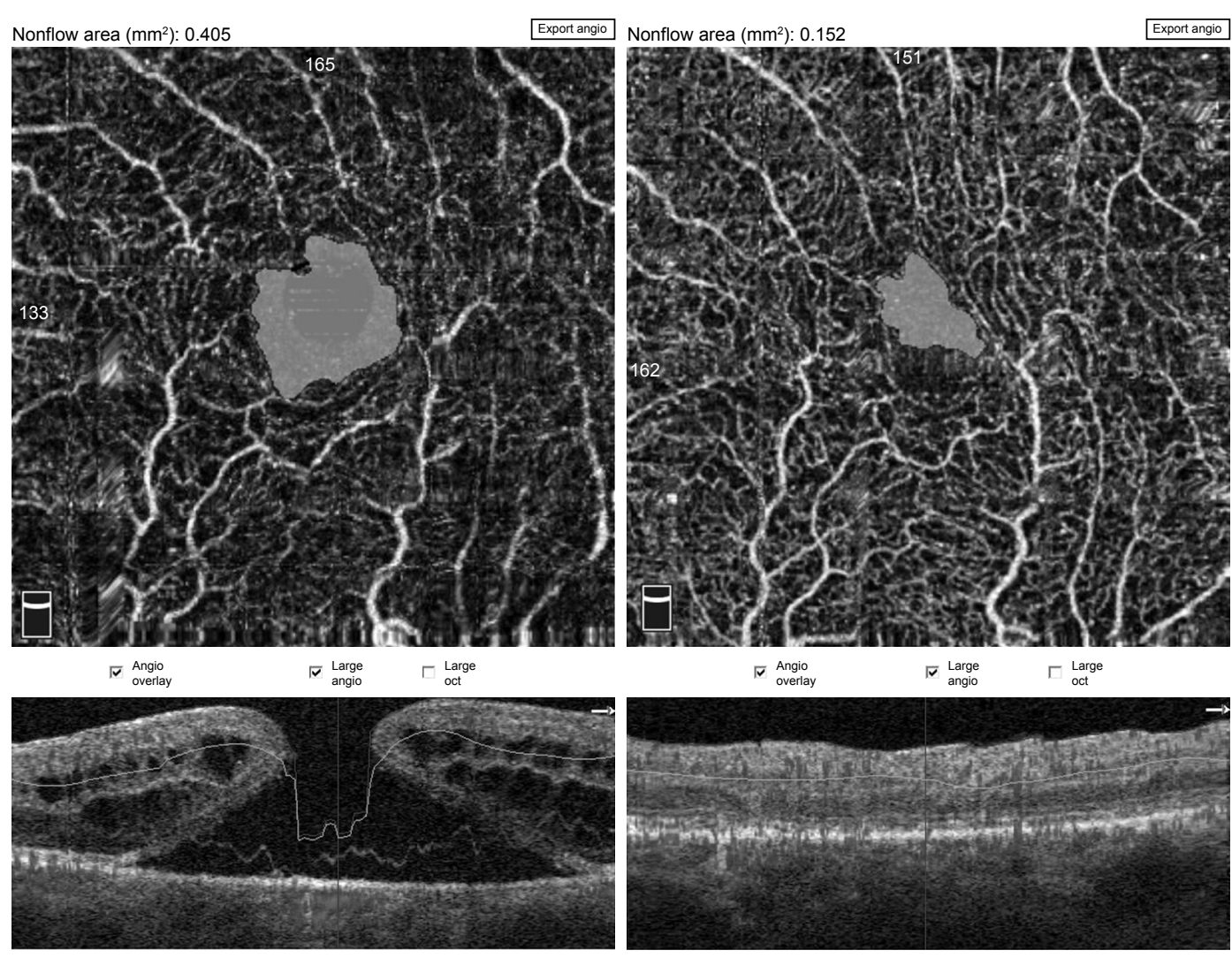

Figure I Pre- and postoperative FAZ measurement using a nonflow software in an 82-year-old male patient. Note: FAZ decreased from $0.405 \mathrm{~mm}^{2}$ preoperatively to $0.152 \mathrm{~mm}^{2}$ postoperatively. Abbreviation: FAZ, foveal avascular zone.

The fovea vessel density (FVDS) was measured on SCP images using a density function on the AngioAnalytics software. Qualitative data consisted of retinal vascular density color perfusion maps generated for each microvascular layer. In the color maps, bright red represents a density of greater than $50 \%$ perfused vessels, dark blue represents no perfused vessels, and intermediate perfusion densities are color coded accordingly. From OCT thickness inner limiting membrane:retinal pigment epithelium (ILM-RPE) and Vessel Density Report, we obtained the data about FVDS (in \% perfused vessels) as well as a central retinal thickness (CRT) values (in $\mu \mathrm{m}$ ) (Figure 2).

The en face images of the choriocapillary plexus were segmented with inner and outer boundaries at 31 and $59 \mu \mathrm{m}$, respectively, beneath the RPE-Reference Offset. Parafoveal choriocapillary flow area (in $\mathrm{mm}^{2}$ ) was measured on the choriocapillary slab using the flow function of the AngioAnalytics software with a circle of $1.0 \mathrm{~mm}$ radius centered in the middle of image. The flow area in choriocapillaries within the circle in chosen area is measured automatically by imaging software. The selected measurement area pre- and postoperatively was always $3.14 \mathrm{~mm}^{2}$ (based on a circle of $1 \mathrm{~mm}$ radius) (Figure 3 ).

Statistical analysis was performed using IBM SPSS Statistics software. Statistical results were considered significant at $P<0.05$. Normality of parameters was assessed with the Shapiro-Wilk test. Student's $t$-test was used for dependent samples. We used Pearson correlation coefficient $(r)$ to measure the strength of linear relationship between two variables.

\section{Results}

Mean preoperative BCVA of MH eyes was $0.1 \pm 0.11$ and improved to $0.42 \pm 0.17$ at the final visit $(P<0.001)$. Mean basal hole size in $\mathrm{MH}$ eyes was $937.39 \mu \mathrm{m}$, mean minimum hole diameter was $446.14 \mu \mathrm{m}$. The hole was closed in all cases after initial surgery, which was confirmed in OCT examination. The mean area of superficial FAZ preoperatively was $0.39 \pm 0.07 \mathrm{~mm}^{2}$ and was reduced to $0.24 \pm 0.07 \mathrm{~mm}^{2}$ postoperatively $(P<0.001)$. The mean CRT in $\mathrm{MH}$ eyes was $396.75 \pm 62.6 \mu \mathrm{m}$ preoperatively and was reduced to $272.17 \pm 30.7 \mu \mathrm{m}$ postoperatively $(P<0.001)$. En face images 


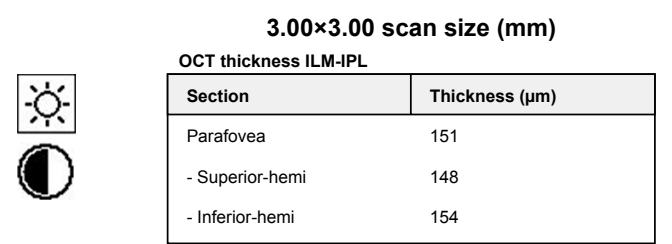

\begin{tabular}{|c|c|c|c|}
\hline & \multicolumn{3}{|c|}{ OCT thickness ILM-RPE and vessel density } \\
\hline & Density (\%) & Section & Thickness $(\mu \mathrm{m})$ \\
\hline \multirow[t]{3}{*}{$\begin{array}{c}\text { Save } \\
\text { analytic }\end{array}$} & 45.98 & Whole image & N/A \\
\hline & 29.83 & Fovea & 531 \\
\hline & 47.57 & Parafovea & 509 \\
\hline Reference & 47.16 & - Superior-hemi & 494 \\
\hline C. Superficial & 47.99 & - Inferior-hemi & 525 \\
\hline $\begin{array}{l}C \text { Deep } \\
C \text { Outer retina }\end{array}$ & 49.05 & - Tempo & 560 \\
\hline C Choroid cap & 45.34 & - Superior & 475 \\
\hline $\begin{array}{l}\text { Upper - ILM } \\
\text { offset }(\mu \mathrm{m})\end{array}$ & & - Nasal & 471 \\
\hline $\begin{array}{ll}3 & \ldots \\
\end{array}$ & 46.67 & - Inferior & 534 \\
\hline $\begin{array}{l}\text { Lower - IPL } \\
\text { offset (um) }\end{array}$ & \multicolumn{3}{|c|}{ Grid-based vessel density (\%) } \\
\hline \multirow{3}{*}{$\begin{array}{ll}16 & \ldots\end{array}$} & 48.82 & 45.90 & 45.71 \\
\hline & 49.14 & 32.55 & 51.54 \\
\hline & 49.07 & 49.30 & 41.45 \\
\hline
\end{tabular}

『 Auto zoom $\oplus \mid \Theta$

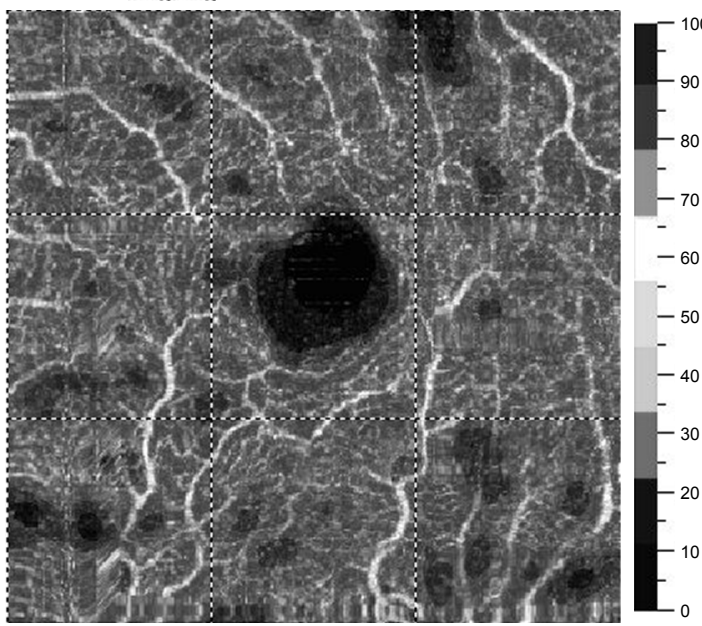

$3.00 \times 3.00$ scan size $(\mathrm{mm})$

\begin{tabular}{|l|l|l|}
\hline \multicolumn{2}{|l|}{ OCT thickness ILM-IPL } \\
\cline { 2 - 3 } & Section & Thickness $(\mu \mathrm{m})$ \\
\cline { 2 - 3 } & Parafovea & 113 \\
& - Superior-hemi & 106 \\
- Inferior-hemi & 119
\end{tabular}

\begin{tabular}{|c|c|c|c|}
\hline & \multicolumn{3}{|c|}{ OCT thickness ILM-RPE and vessel density } \\
\hline & Density (\%) & Section & Thickness $(\mu \mathrm{m})$ \\
\hline \multirow[t]{3}{*}{$\begin{array}{c}\text { Save } \\
\text { analytic }\end{array}$} & 50.81 & Whole image & N/A \\
\hline & 38.73 & Fovea & 253 \\
\hline & 51.83 & Parafovea & 301 \\
\hline Reference & 52.49 & - Superior-hemi & 298 \\
\hline (C) Superficial & 51.22 & - Inferior-hemi & 305 \\
\hline $\begin{array}{l}\Upsilon \text { Deep } \\
\Upsilon \text { Outer retina }\end{array}$ & 49.59 & - Tempo & 265 \\
\hline C Choroid cap & 56.06 & - Superior & 302 \\
\hline $\begin{array}{l}\text { Upper - ILM } \\
\text { offset }(\mu \mathrm{m})\end{array}$ & 50.97 & - Nasal & 312 \\
\hline $3 \ldots$ & 51.50 & - Inferior & 327 \\
\hline
\end{tabular}

Lower - IPL Grid-based vessel density (\%) offset $(\boldsymbol{\mu m})$

\begin{tabular}{lll}
54.67 & 52.97 & 48.46 \\
52.61 & 40.32 & 51.19 \\
53.14 & 53.07 & 50.55 \\
\hline
\end{tabular}

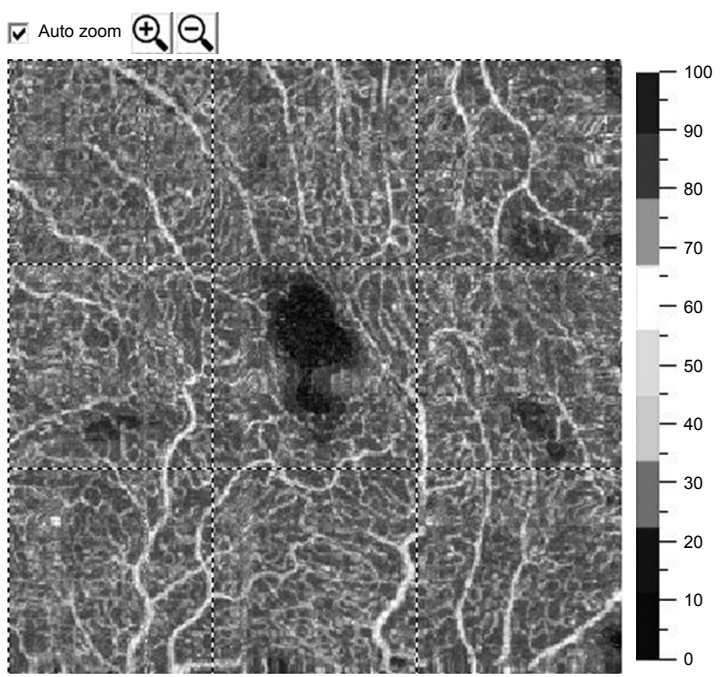

Figure 2 The fovea vessel density (FVDS) measured in superficial capillary plexus (SCP) using a density function on the imaging software.

Notes: In vascular density color perfusion maps, bright red represents a density of greater than $50 \%$ perfused vessels, dark blue represents no perfused vessels, and intermediate perfusion densities are color coded accordingly. In presented case example of 82 -year-old male patient, the increase of FVDS from $29.83 \%$ to $38.73 \%$ after surgery is to observe. The ischemic areas decreased significantly. We observe a reduction of central retinal thickness from 531 to $253 \mu \mathrm{m}$ postoperatively.

of the middle retina showed the preoperative cystic areas surrounding the hole in all $\mathrm{MH}$ eyes with resolution of the $\mathrm{MH}$ and adjacent cystic areas in all cases. A representative case is shown in Figures 4A, B and 5A, B.

The mean preoperative parafoveal choriocapillary flow area in $\mathrm{MH}$ eyes was $1.59 \pm 0.28 \mathrm{~mm}^{2}$. Postoperative mean choriocapillary flow area in parafovea increased significantly to $1.93 \pm 0.03 \mathrm{~mm}^{2}$. Mean FVDS in SCP was $29.84 \% \pm 4.17 \%$ preoperatively and increased to $35.02 \% \pm 3.47 \%$ postoperatively $(P<0.001)$.
The $r$-Pearson correlation coefficient between the initial MHS and the BCVA after the treatment was measured: $r=-0.47 ; P<0.05$, the correlation was statistically significant. There is a moderate and negative correlation between these two variables. High values of one variable are accompanied by low values of the other variable (Figure 6A). There is a very strong correlation between the initial MHS and the MCFA before the treatment $r=-0.729 ; P<0.01$. The bigger MHS was corresponding with lower parafoveal choriocapillary flow area (Figure 6B). There was no statistical 

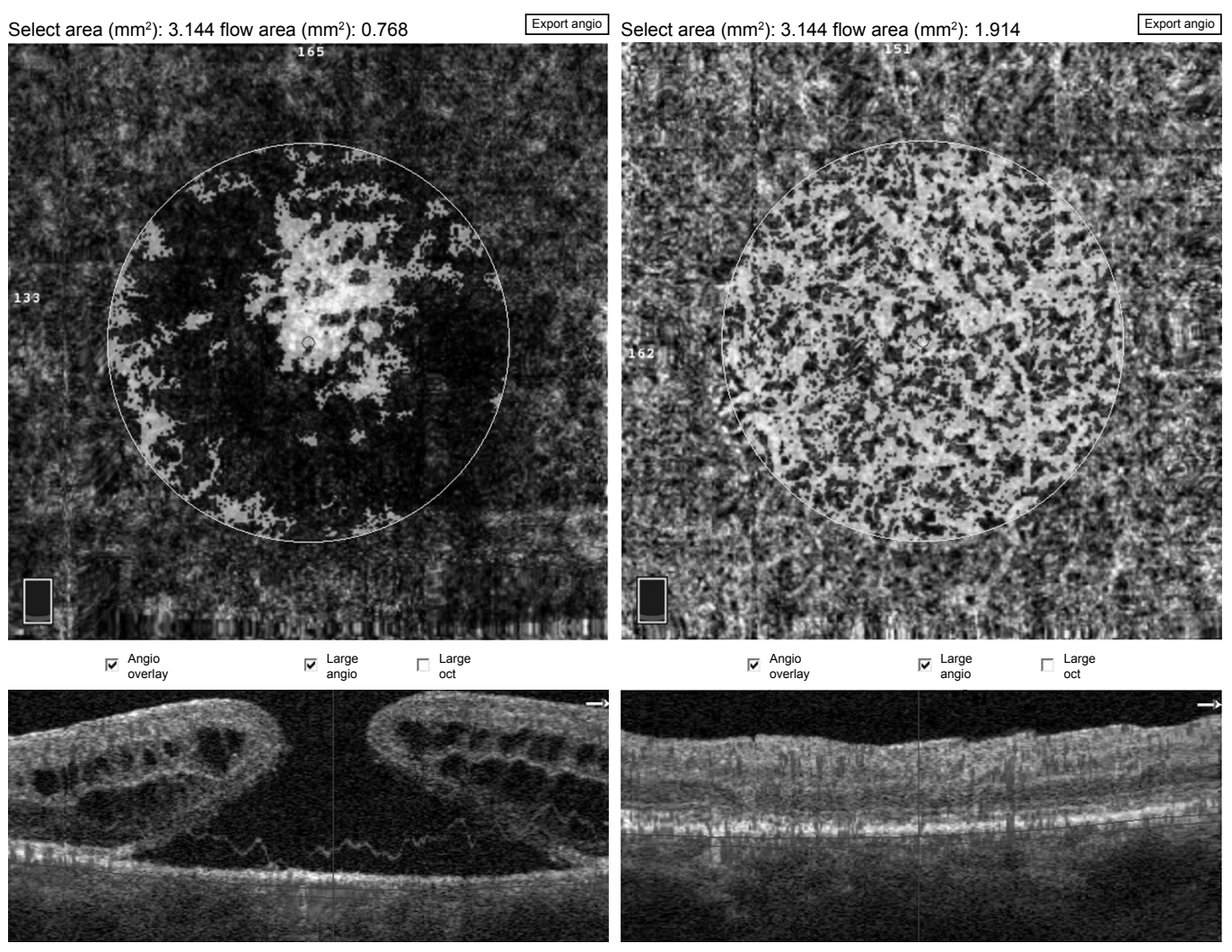

Figure 3 Pre- and postoperative choriocapillary flow area measurement using a flow tool of imaging software.

Note: This example shows a case of 82 -year-old male patient with an increase in choriocapillary flow area from $0.768 \mathrm{~mm}^{2}$ preoperatively to $1.914 \mathrm{~mm}{ }^{2}$ postoperatively.

correlation between the initial MHS and FVDS in SCP before $(r=0.018 ; P>0.05)$ and after the surgical treatment $(r=0.222 ; P>0.05)$. There was also no statistically significant correlation between preoperative FAZ and BCVA before the treatment $(r=0.369 ; P>0.05)$, but we found a relatively strong negative correlation between preoperative FAZ and postoperative BCVA $(r=-0.59, P<0.01)$ (Figure 6C). There was also a strong correlation between BCVA and CRT after the treatment $(r=0.6 ; P<0.01)$; higher postoperative CRT values were corresponding with lower BCVA outcomes postoperatively (Figure 6D). Moreover, there was neither a correlation between preoperative superficial fovea vessel density (FVDS) and BCVA postoperatively nor between preoperative MCFA and BCVA after the surgical treatment.

\section{Discussion}

In our study, we investigated the morphological and vascular OCTA features of idiopathic MHs before and after surgical treatment. Regarding the superficial and deep vascular network as seen on OCTA, pre- and postoperative comparisons confirmed structural recovery following surgery. As previously described by Shahlaee et $a l,{ }^{47}$ in our study we observed resolution of the cystic changes in the middle retina on en face scans, which likely resulted in contraction of the FAZ with blood vessels and retinal tissue replacing the fluid-filled cystic areas with subsequent reduction of CRT. Other previous OCT studies have similarly demonstrated the dynamic healing process that occurs after surgical repair of MHs. ${ }^{48}$ In our study, we observed postoperatively a statistically important increase of FVDS in SCP as well as an increase of flow area in choriocapillary network in OCTA. Moreover, we observe a statistically important reduction of FAZ postoperatively. This shows the potential for recovery due to neuronal and vascular plasticity and suggests that the healing process after MH surgery may be involved in both anatomic and hemodynamic changes of the inner retina.

We evaluated the relationship between vascular changes in OCTA and visual outcomes (BCVA postoperatively). Neither FVDS in superficial capillary network nor choriocapillary flow area (MCFA) was associated with final visual acuity, but we found a relatively strong correlation between preoperative FAZ and postoperative BCVA. The influence of FAZ size and its reduction following surgery on visual acuity outcomes may be an area worth exploring. We observed a 


\section{A Angio structure-function}

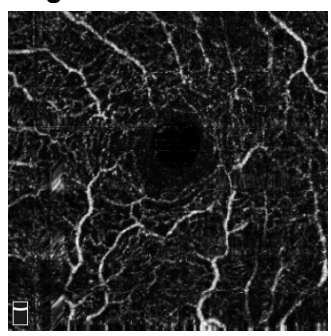

Angio/OCT - superficial
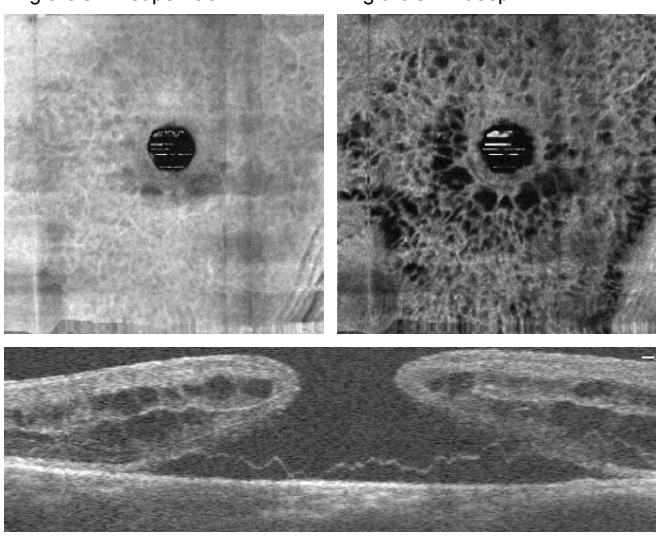

B Angio structure-function

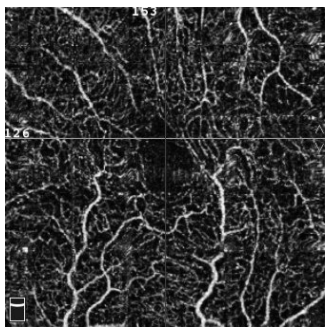

Angio/OCT - superficial
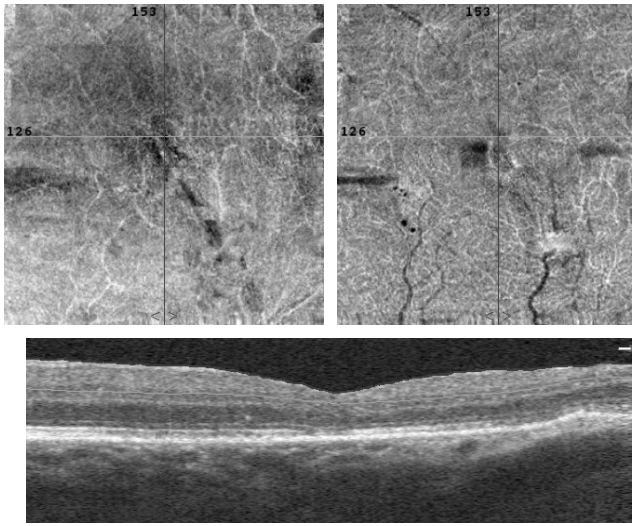

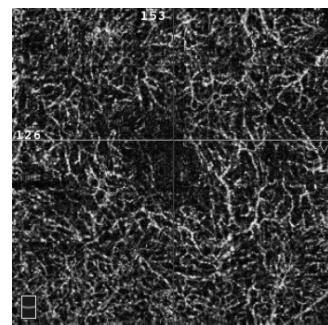

Angio/OCT - deep

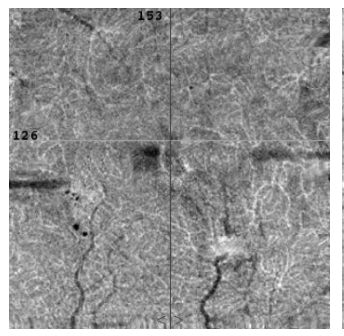

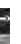

.
$3.00 \times 3.00$ scan size $(\mathrm{mm})$

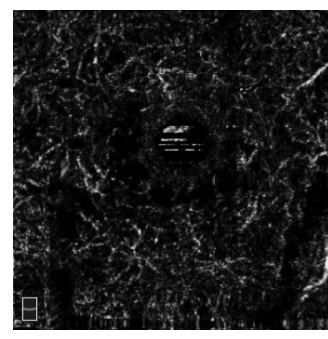

Angio/OCT - deep
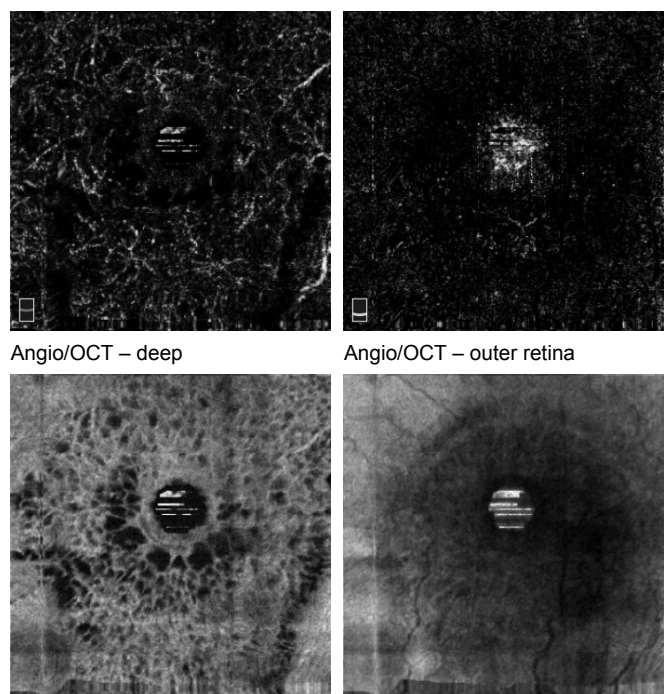

Angio/OCT - outer retina
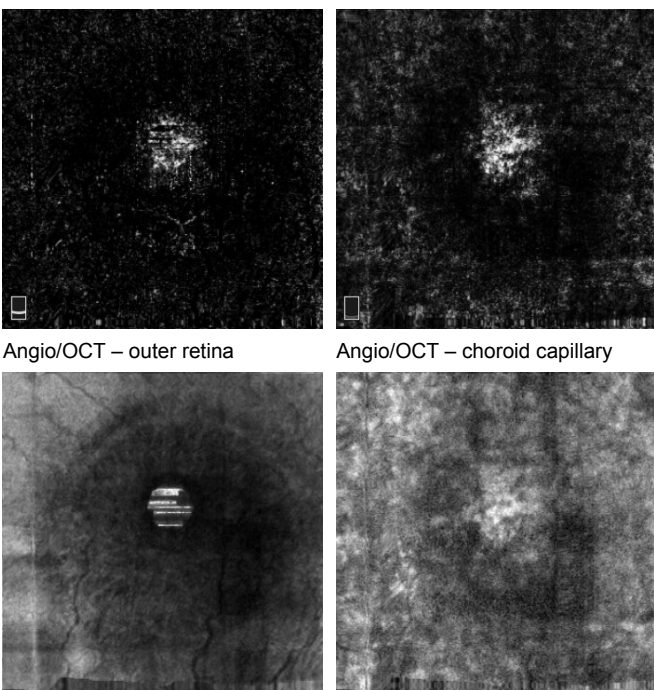

Angio/OCT - choroid capillary
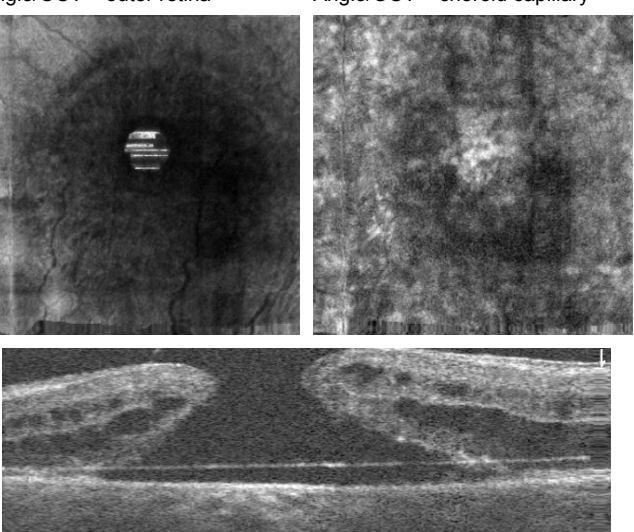

Left/OS

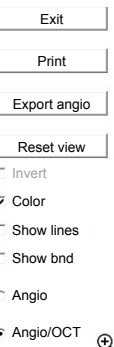

Angio/OCT $\oplus$

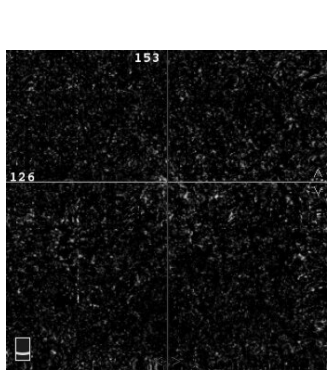

Angio/OCT - outer retina
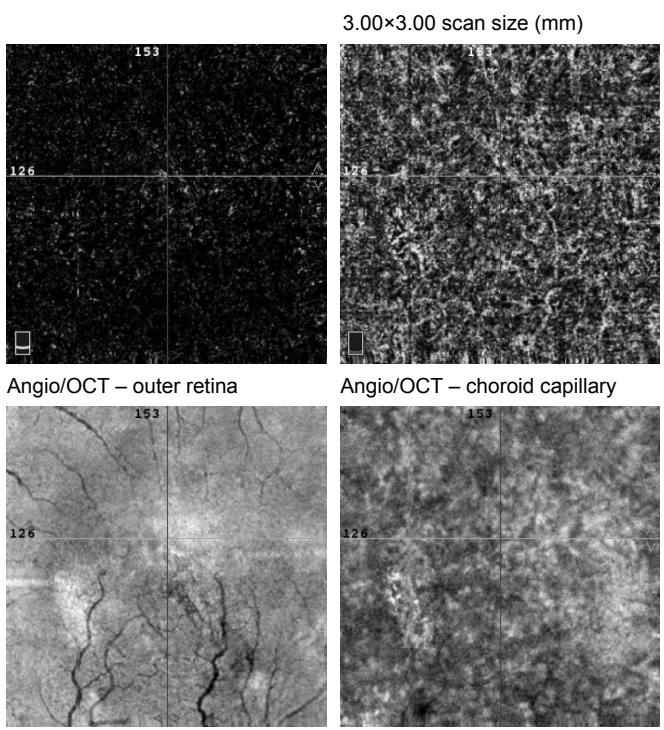

Angio/OCT - choroid capillary
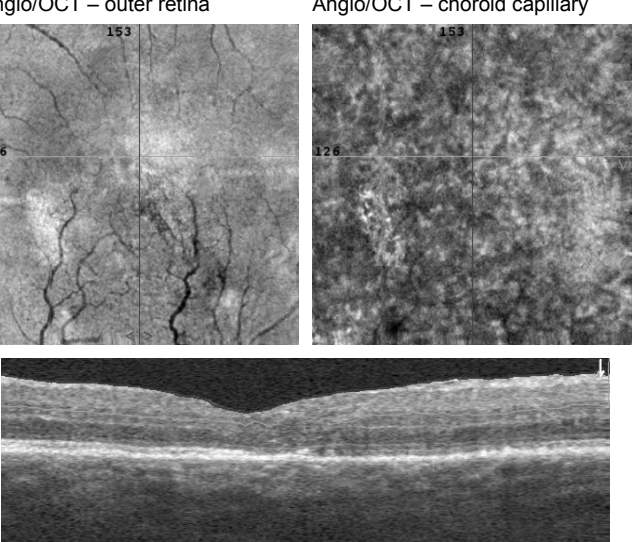

Figure 4 Pre- and post- operative OCTA of 82-year-old patient's left eye.

Notes: (A) Preoperative OCTA report of 82-year-old male patient's left eye showing numerous cystic changes in middle retina in en face scans. Macular basal hole size is $2,146 \mu \mathrm{m}$, minimum hole diameter is $427 \mu \mathrm{m}$. BCVA preoperatively was 0.08 . (B) Postoperative OCTA scans of the same case as presented above. We observe in OCTA and en face scans the resolution of macular hole and adjacent cystic areas with normalization of foveal morphology and reduction of central retinal thickness. BCVA improved to 0.3 after surgery.

Abbreviations: BCVA, best-corrected visual acuity; OCT, optical coherence tomography; OCTA, optical coherence tomography angiography.

significant increase of choriocapillary flow postoperatively. The mechanisms of impairment or restoration of choriocapillaris in FTMH remain unclear. A possible explanation would be that the restoration of choriocapillaris is associated with restoration of retinal structure. ${ }^{49}$ The major blood supply to the retina is the choroid because the photoreceptors are extremely metabolically active. There is a continuous flow of ions and water across the retina and RPE into the 
A Angio structure-function

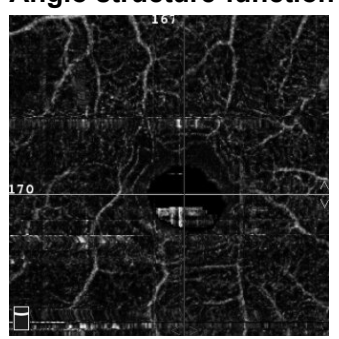

Angio/OCT - superficial
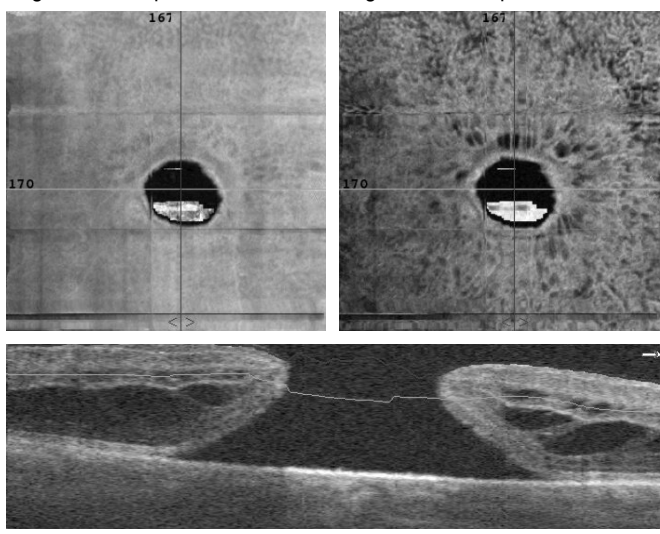

B Angio structure-function

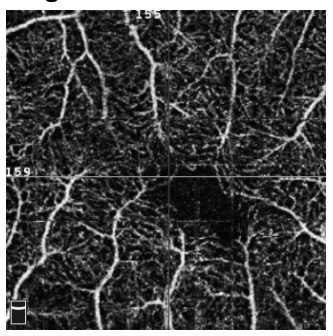

Angio/OCT - superficial
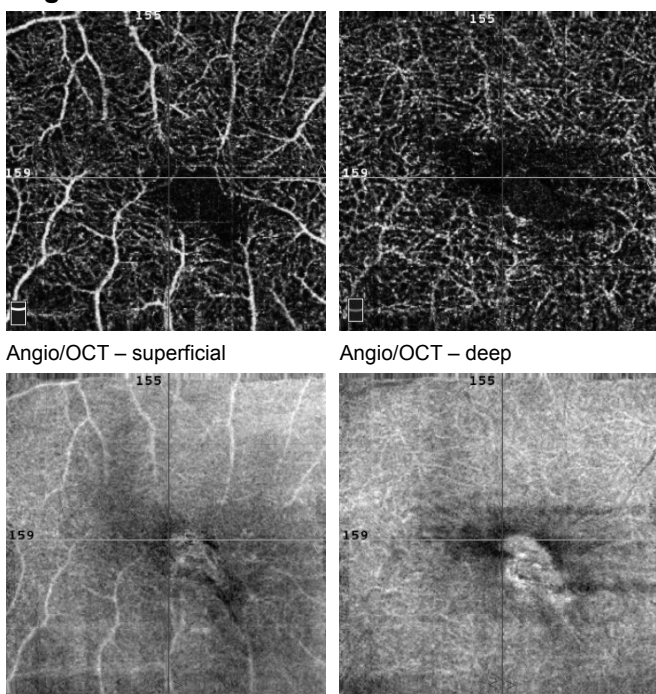

Angio/OCT - deep
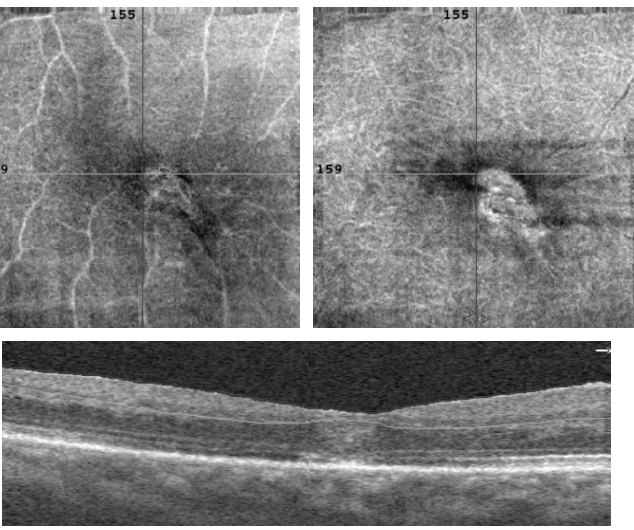

Angio/OCT - deep

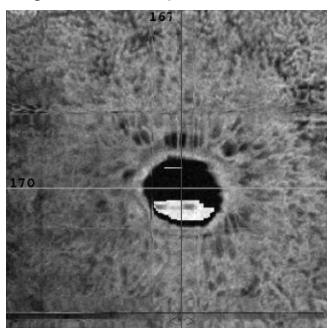

$3.00 \times 3.00$ scan size $(\mathrm{mm})$

Right/OD

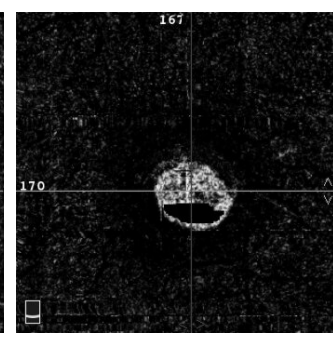

Angio/OCT - outer retina
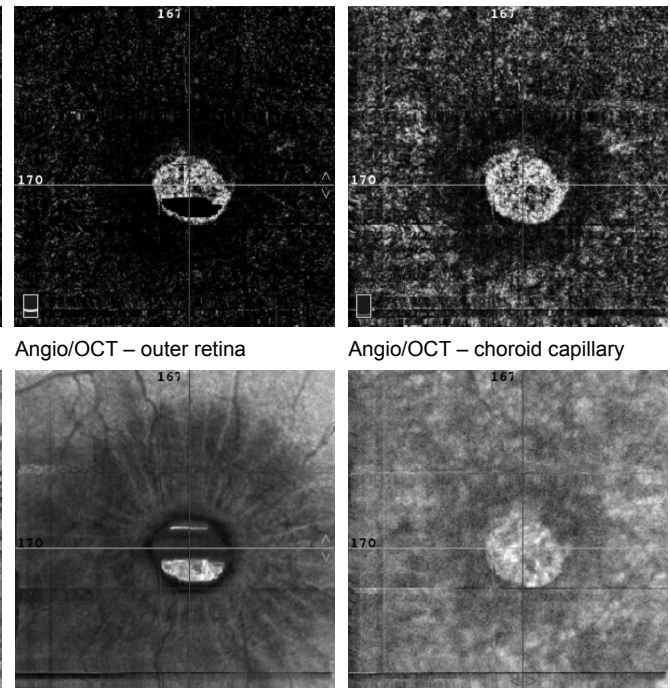

Angio/OCT - choroid capillary
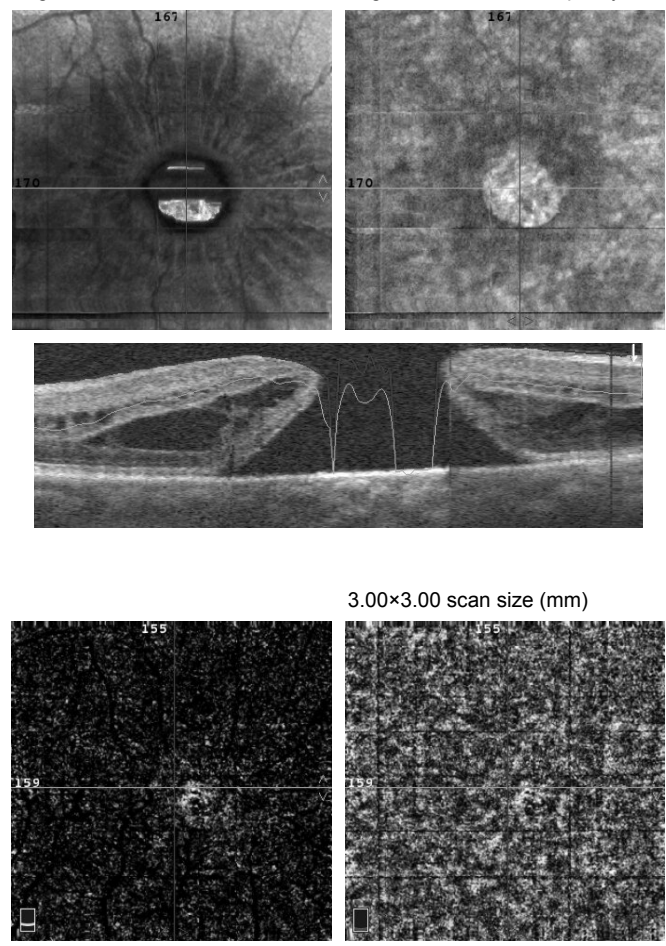

Angio/OCT - outer retina

$3.00 \times 3.00$ scan size $(\mathrm{mm})$

Right/OD

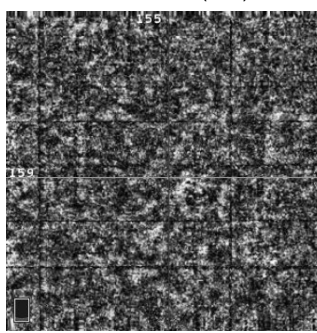

Angio/OCT - choroid capillary
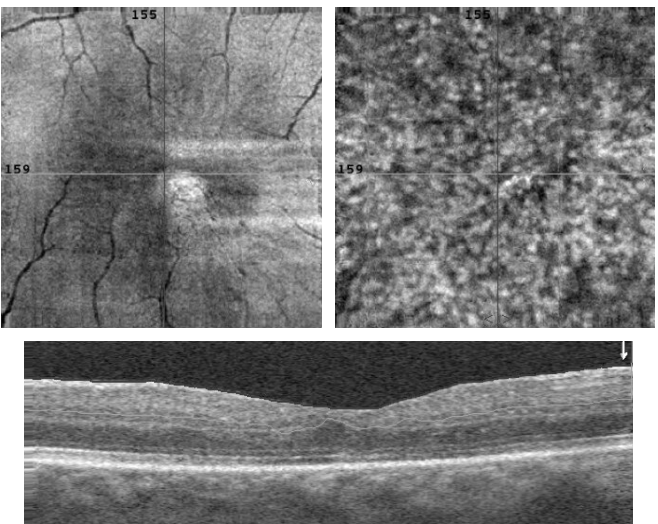

Figure 5 Pre- and post- operative OCTA of 75-year-old patient's right eye.

Notes: (A) Preoperative OCTA report of 75-year-old female patient's right eye showing numerous cysts in middle retina in en face scans. Macular basal hole size is I,565 $\mu \mathrm{m}$, minimum hole diameter is $699 \mu \mathrm{m}$. BCVA preoperatively was 0.08. (B) Postoperative OCTA scans of the same patient as presented above. We observe in OCTA and en face scans the resolution of macular hole and adjacent cystic areas with reduction of central retinal thickness. BCVA improved to 0.4 after surgery.

Abbreviations: BCVA, best-corrected visual acuity; OCT, optical coherence tomography; OCTA, optical coherence tomography angiography.

choroid. ${ }^{52}$ It has been suggested that the modulation of this flow may modulate the choroid..$^{53}$ The choriocapillaris in the foveomacular zone has a homogeneous structure. It has been suggested that foveomacular blood flow is determined by pressure gradients and differences in metabolic requirements within the macular retina. ${ }^{54}$ The choroidal lobuli comprising the choriocapillaris layer of the choroid is also thought to determine the flow of blood based on both structure (lobuli) 
A

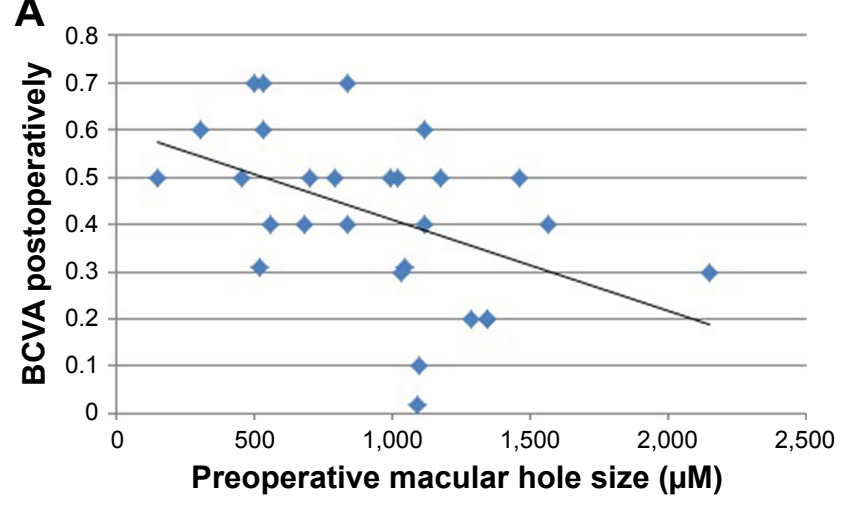

C

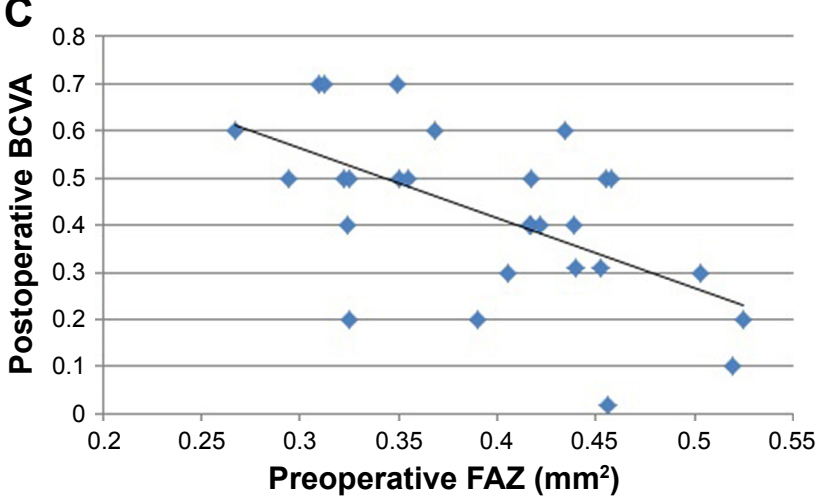

B

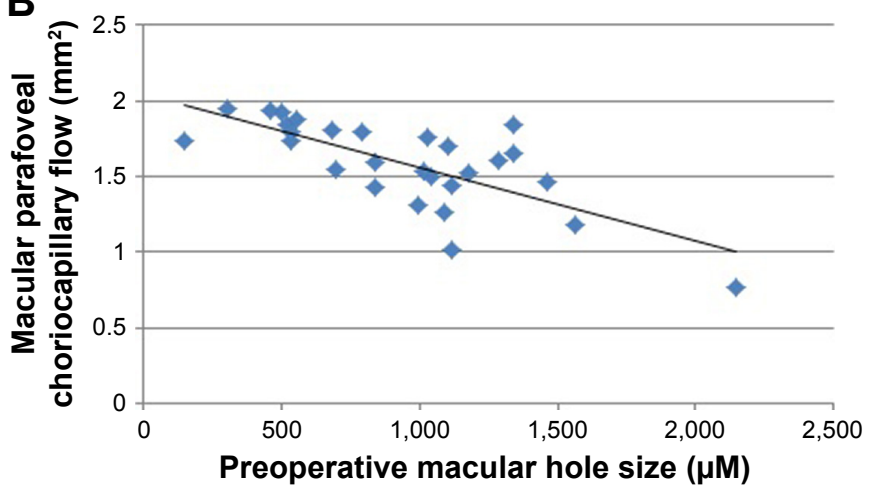

D

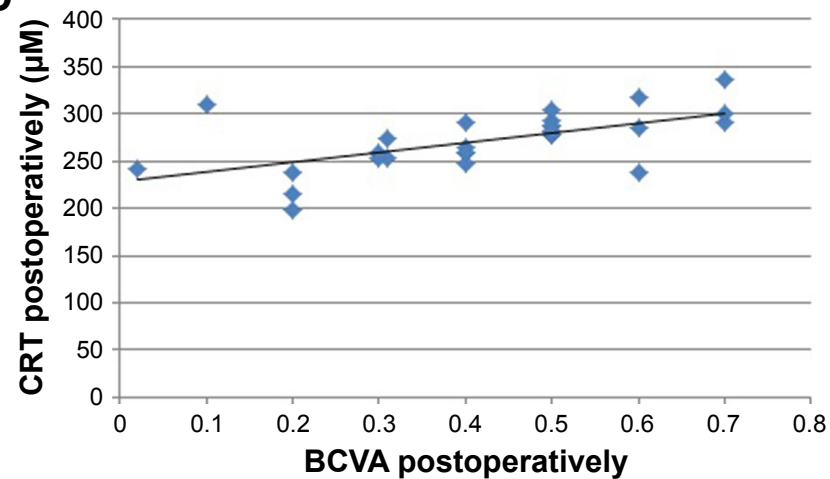

Figure 6 The $r$-Pearson correlation coefficient between the initial MHS and the BCVA.

Notes: (A) Relationship between preoperative macular hole size (MHS) and best-corrected visual acuity (BCVA). (B) Relationship between preoperative MHS and macular parafoveal choriocapillary flow. (C) Relationship between preoperative FAZ and postoperative BCVA. (D) Relationship between postoperative BCVA and postoperative CRT. Abbreviations: CRT, central retinal thickness; FAZ, foveal avascular zone.

and function (neuroretinal activity). ${ }^{55}$ Restoration of ions and water flow from sealed $\mathrm{MH}$ could help explain the restoration of choriocapillaris after the closure of FTMH.

Previous studies confirmed that postoperative photoreceptor layer status was associated with visual acuity. ${ }^{50}$ This could mean that retinal vascular change might not be related to visual prognosis, which is consistent with other previous studies. ${ }^{41,42,51}$ Our report has several limitations, such as small number of eyes and short postoperative observation period. We also did not evaluate in this study other than BCVA functional outcomes such as microperimetry or visual field. The relatively large MHS might be a bias, so the observation may not apply to all MHs, and further investigations are needed.

Although we showed that retinal vascular change was not related to visual outcome, further studies on a larger sample size and longer observation period with diverse tools for measurement of visual function are needed.

\section{Conclusion}

In summary, surgically closed $\mathrm{MH}$ eyes showed reduction of FAZ and increase of FVDS and choriocapillary flow area compared with these parameters preoperatively. We observed reduction of CRT and resolution of cystic changes in en face images after surgery. These results suggest that both anatomic and hemodynamic changes may be involved in the healing process of MH after surgery.

Quantitative evaluation of vascular and morphological changes following idiopathic full-thickness MH surgery using OCTA shows the potential for recovery due to vascular and neuronal plasticity. ${ }^{47}$ OCTA showing vascular changes and their quantitative characteristics might be a useful tool for the assessment of MHs before and after surgical treatment.

\section{Institution where the work was completed}

University Clinical Center, Department of Ophthalmology, School of Medicine in Katowice, Medical University of Silesia, Katowice, Poland.

\section{Disclosure}

The authors report no conflicts of interest in this work.

\section{References}

1. Knapp H. Über isolierte zerreissungen der aderhaut in folge von traumen auf dem augapfel. Arch Augenheilkd. 1869;1:6-12. 
2. Collins ET. Unusual changes to the macular region. Trans Ophthalmol Soc UK. 1900;20:196-197.

3. Noyes HD. Detachment of the macula with laceration of the macula lutea. Trans Am Ophthalmol Soc. 1871;1(8):128-134.

4. Yaoeda H. Clinical observation on macular hole. Acta Soc Ophthalmol Jpn. 1967;71(9):1723-1736. Japanese.

5. Aaberg TM, Blair CJ, Gass JD. Macular holes. Am J Ophthalmol. 1970; 69(4):555-562.

6. Aaberg TM. Macular holes: a review. Surv Ophthalmol. 1970;15: 139-162.

7. Gass JD. Stereoscopic Atlas of Macular Diseases: Diagnosis and Treatment. St Louis: CV Mosby; 1970:195-199.

8. Margheria RR, Schepens CL. Macular breaks. 1. Diagnosis, etiology, and observations. Am J Ophthalmol. 1972;74(2):219-232.

9. James M, Feman SS. Macular holes. Albrecht von Graefes Arch Klin Exp Ophthalmol. 1980;215(1):59-63.

10. McDonnell PJ, Fine SL, Hillis AI. Clinical features of idiopathic macular cysts and holes. Am J Ophthalmol. 1982;93(6):777-786.

11. Morgan CM, Schatz H. Idiopathic macular holes. Am J Ophthalmol. 1985;99(4):437-444.

12. Morgan CM, Schatz H. Involutional macular thinning. A pre-macular hole condition. Ophthalmology. 1986;93(2):153-161.

13. Trempe CL, Weiter JJ, Furukawa H. Fellow eyes in cases of macular hole. Biomicroscopic study of the vitreous. Arch Ophthalmol. 1986;104(1):93-95.

14. Gass JD. Stereoscopic Atlas of Macular Diseases: Diagnosis and Treatment. St Louis: CV Mosby; 1987:684-693.

15. Gass JD. Idiopathic senile macular hole: its early stages and development. Arch Ophthalmol. 1988;106(5):629-639.

16. Johnson RN, Gass JD. Idiopathic macular holes. Observations, stages of formation, and implications for surgical intervention. Ophthalmology. 1988;95(7):917-924.

17. Ezra E. Idiopathic full thickness macular hole: natural history and pathogenesis. Br J Ophthalmol. 2001;85(1):102-109.

18. Smiddy WE, Flynn HW Jr. Pathogenesis of macular holes and therapeutic implications. Am J Ophthalmol. 2004;137(3):525-537.

19. Kelly NE, Wendel RT. Vitreous surgery for idiopathic macular holes. Results of a pilot study. Arch Ophthalmol. 1991;109(5):654-659.

20. Wendel RT, Patel AC, Kelly NE, Salzano TC, Wells JW, Novack GD Vitreous surgery for macular holes. Ophthalmology. 1993;100(11): 1671-1676.

21. Ryan EH Jr, Gilbert HD. Results of surgical treatment of recent-onset full-thickness idiopathic macular holes. Arch Ophthalmol. 1994;112(12): 1545-1553.

22. Brooks HL Jr. Macular hole surgery with and without internal limiting membrane peeling. Ophthalmology. 2000;107(10):1939-1948; discussion 1948-1949.

23. Duker JS, Kaiser PK, Binder S, et al. The International Vitreomacular Traction Study group classification of vitreomacular adhesion, traction, and macular hole. Ophthalmology. 2013;120(12):2611-2619.

24. Kusuhara S, Teraoka Escaño MF, Fujii S, et al. Prediction of postoperative visual outcome based on hole configuration by optical coherence tomography in eyes with idiopathic macular holes. Am J Ophthalmol. 2004;138(5):709-716.

25. Matet A, Savastano MC, Rispoli M, et al. En face optical coherence tomography of foveal microstructure in full-thickness macular hole: a model to study perifoveal Müller cells. Am J Ophthalmol. 2015;159(6): 1142.e3-1151.e3.

26. Tanner V, Chauhan DS, Jackson TL, Williamson TH. Optical coherence tomography of the vitreoretinal interface in macular hole formation. Br J Ophthalmol. 2001;85(9):1092-1097.

27. Woon WH, Greig D, Savage MD, et al. Movement of the inner retina complex during the development of primary full-thickness macular holes: implications for hypotheses of pathogenesis. Graefes Arch Clin Exp Ophthalmol. 2015;253(12):2103-2109.

28. Yun C, Oh J, Hwang SY, Togloom A, Kim SW, Huh K. Morphologic characteristics of chronic macular hole on optical coherence tomography. Retina. 2012;32(10):2077-2084.
29. Michalewska Z, Michalewski J, Nawrocki J. Continuous changes in macular morphology after macular hole closure visualized with spectral optical coherence tomography. Graefes Arch Clin Exp Ophthalmol. 2010;248(9):1249-1255.

30. Balducci N, Morara M, Veronese C, Torrazza C, Pichi F, Ciardella AP. Retinal nerve fiber layer thickness modification after internal limiting membrane peeling. Retina. 2014;34(4):655-663.

31. Ishida M, Ichikawa Y, Higashida R, Tsutsumi Y, Ishikawa A, Imamura Y. Retinal displacement toward optic disc after internal limiting membrane peeling for idiopathic macular hole. Am J Ophthalmol. 2014;157(5):971-977.

32. Itoh $\mathrm{Y}$, Inoue $\mathrm{M}$, Rii $\mathrm{T}$, Hiraoka $\mathrm{T}$, Hirakata A. Correlation between length of foveal cone outer segment tips line defect and visual acuity after macular hole closure. Ophthalmology. 2012;119(7):1438-1446.

33. Kawano K, Ito Y, Kondo M, et al. Displacement of foveal area toward optic disc after macular hole surgery with internal limiting membrane peeling. Eye (Lond). 2013;27(7):871-877.

34. Kim JH, Kang SW, Park DY, Kim SJ, Ha HS. Asymmetric elongation of foveal tissue after macular hole surgery and its impact on metamorphopsia. Ophthalmology. 2012;119(10):2133-2140.

35. Kumagai K, Hangai M, Larson E, Ogino N. Progressive changes of regional macular thickness after macular hole surgery with internal limiting membrane peeling. Invest Ophthalmol Vis Sci. 2013;54(7):4491-4497.

36. Nukada K, Hangai M, Ooto S, Yoshikawa M, Yoshimura N. Tomographic features of macula after successful macular hole surgery. Invest Ophthalmol Vis Sci. 2013;54(4):2417-2428

37. Oh IK, Oh J, Yang SM, Ahn SE, Kim SW, Huh K. Hyperreflective external limiting membranes after successful macular hole surgery. Retina. 2012;32(4):760-766.

38. Oh J, Smiddy WE, Flynn HW Jr, Gregori G, Lujan B. Photoreceptor inner/outer segment defect imaging by spectral domain OCT and visual prognosis after macular hole surgery. Invest Ophthalmol Vis Sci. 2010;51(3):1651-1658.

39. Oh J, Yang SM, Choi YM, Kim SW, Huh K. Glial proliferation after vitrectomy for a macular hole: a spectral domain optical coherence tomography study. Graefes Arch Clin Exp Ophthalmol. 2013;251(2):477-484.

40. Ohta K, Sato A, Fukui E. Retinal thickness in eyes with idiopathic macular hole after vitrectomy with internal limiting membrane peeling. Graefes Arch Clin Exp Ophthalmol. 2013;251(5):1273-1279.

41. Ooka E, Mitamura Y, Baba T, Kitahashi M, Oshitari T, Yamamoto S. Foveal microstructure on spectral-domain optical coherence tomographic images and visual function after macular hole surgery. Am J Ophthalmol. 2011;152(2):283.e1-290.e1.

42. Wakabayashi T, Fujiwara M, Sakaguchi H, Kusaka S, Oshima Y. Foveal microstructure and visual acuity in surgically closed macular holes: spectral-domain optical coherence tomographic analysis. Ophthalmology. 2010;117(9):1815-1824.

43. Yun C, Ahn J, Kim M, et al. Characteristics of retinal vessels in surgically closed macular hole: an optical coherence tomography angiography study. Graefes Arch Clin Exp Ophthalmol. 2017;255(10):1923-1934.

44. Spaide RF, Klancnik JM Jr, Cooney MJ. Retinal vascular layers imaged by fluorescein angiography and optical coherence tomography angiography. JAMA Ophthalmol. 2015;133(1):45-50.

45. Rizzo S, Savastano A, Bacherini D, Savastano MC. Vascular features of full-thickness macular hole by OCT angiography. Ophthalmic Surg Lasers Imaging Retina. 2017;48(1):62-68.

46. Teng Y, Yu M, Wang Y, Liu X, You Q, Liu W. OCT angiography quantifying choriocapillary circulation in idiopathic macular hole before and after surgery. Graefes Arch Clin Exp Ophthalmol. 2017;255(5): 893-902.

47. Shahlaee A, Rahimy E, Hsu J, Gupta OP, Ho AC. Preoperative and postoperative features of macular holes on en face imaging and optical coherence tomography angiography. Am J Ophthalmol Case Rep. 2017;5:20-25

48. Grewal DS, Reddy V, Mahmoud TH. Assessment of foveal microstructure and foveal lucencies using optical coherence tomography radial scans following macular hole surgery. Am J Ophthalmol. 2015;160(5): 990.e1-999.e1. 
49. Ahn J, Yoo G, Kim JT, Kim SW, Oh J. Choriocapillaris layer imaging with swept-source optical coherence tomography angiography in lamellar and full-thickness macular hole. Graefes Arch Clin Exp Ophthalmol. 2018;256(1):11-21.

50. Sano M, Shimoda Y, Hashimoto H, Kishi S. Restored photoreceptor outer segment and visual recovery after macular hole closure. Am J Ophthalmol. 2009;147(2):313.e1-318.e1.

51. Hashimoto Y, Saito W, Fujiya A, et al. Changes in inner and outer retinal layer thicknesses after vitrectomy for idiopathic macular hole: implications for visual prognosis. PLoS One. 2015;10(8):e0135925.
52. Rymer J, Wildsoet CF. The role of the retinal pigment epithelium in eye growth regulation and myopia: a review. Vis Neurosci. 2005;22(3): 251-261.

53. Nickla DL, Wallman J. The multifunctional choroid. Prog Retin Eye Res. 2010;29(2):144-168.

54. Fryczkowski AW. Anatomical and functional choroidal lobuli. Int Ophthalmol. 1994;18(3):131-141.

55. Lovasik JV, Kergoat H. Systemic determinants. In: Schmetterer L, Kiel JW, editors. Ocular Blood Flow. Springer: New York; 2012: 173-210.
Clinical Interventions in Aging

\section{Publish your work in this journal}

Clinical Interventions in Aging is an international, peer-reviewed journal focusing on evidence-based reports on the value or lack thereof of treatments intended to prevent or delay the onset of maladaptive correlates of aging in human beings. This journal is indexed on PubMed Central, MedLine,

\section{Dovepress}

CAS, Scopus and the Elsevier Bibliographic databases. The manuscript management system is completely online and includes a very quick and fair peer-review system, which is all easy to use. Visit http://www.dovepress. com/testimonials.php to read real quotes from published authors. 